\title{
Two-detector Computed Tomography Map of the Inferior Epigastric Vessels for Percutaneous Transabdominal Intervention Procedures
}

\author{
Hakan Gençhellaç ${ }^{1}$, Memduh Dursun ${ }^{2}$, Osman Temizöz ${ }^{1}$, Bekir Cağl1 ${ }^{1}$, Mustafa K. Demir ${ }^{1}$ \\ ${ }^{1}$ Department of Radiology, Trakya University Faculty of Medicine, Edirne, Turkey \\ ${ }^{2}$ Department of Radiology, İstanbul University Faculty of Medicine, İstanbul, Turkey
}

Background: It is crucial to know anatomic variations and the exact course of an inferior epigastric artery (IEA) to prevent any complications during percutaneous abdominal interventions.

Aims: The aim of this study was to map the inferior epigastric vessels using reconstructed two-detector computed tomography images and measure the distance from the inferior epigastric artery (IEA) to the midline to determine a safe route for percutaneous abdominal interventions.

Study Design: Retrospective comparative study.

Methods: Coronal reconstructed two-detector computed tomography images of 200 patients were evaluated to measure the distances between the IEA and midline at three levels (origin, middle, and distal). Vein and artery arrangements were documented.
Results: The most frequently encountered arrangement (41.5\%) was a single vein and artery on both sides. Mean distances on the right and left sides were 4.01 and $4.47 \mathrm{~cm}$ at the umbilical level, 3.81 and 4.26 $\mathrm{cm}$ at the midlevel, and 5.62 and $5.51 \mathrm{~cm}$ at the origin level. On both sides, measurement differences between the three levels were highly significant $(p<0.05)$. In addition, a total of 56 IEA bifurcations were depicted in all 200 patients. Thirteen of the 56 bifurcations occurred only on the right side, 11 only on the left side, and 32 on both sides.

Conclusion: It is important to be attentive to the IEA's course, at different midline levels, when attempting percutaneous interventions via an abdominal approach. (Balkan Med J 2014;31:72-76).

Key Words: Abdominal approach, inferior epigastric, midline, percutaneous interventions, two-detector computed tomography, vessels
The routine application of various percutaneous abdominal interventions for diagnostic and treatment procedures, such as paracentesis, peritoneal dialysis catheter procedures, tru-cut or fine needle biopsies, manipulation of laparoscopic instruments, insertion of sutures and drains, radiofrequency thermal ablation, abscess drainage, and endoscopic gastrostomy, has increased over the past two decades. Although these procedures can be performed safely, with or without imaging guiding, some complications may occur. Inferior epigastric artery (IEA) injuries are one of the major types of puncture site-related complications that occur in mid and lower abdominal percutaneous interventions. Therefore, it is crucial to be aware of anatomical variations and the exact course of the IEA to prevent any complications during percutaneous abdominal interventions.

Several computed tomography (CT) studies have been published documenting the distance from the IEA to the midline, at different levels in randomized patients (1), and mapping the IEAs and their branches in selected cases (2-4). However, few multidetector CT (MDCT) studies have been performed on the general population revealing the abdominal course of an IEA and measuring its distance to the midline at different levels $(5,6)$.

The purpose of this study was to map the inferior epigastric vessels using reconstructed two-detector computed tomography (TDCT) images and to measure distances from the IEA to the midline to determine a safe route for percutaneous abdominal interventions.

\section{MATERIAL AND METHODS}

\section{Patient population}

The study population was selected from among patients who underwent contrast-enhanced abdominal MDCT examinations in our picture archiving and communication system (PACS). Approval from the Ethical Committee of the hospital was obtained (TÜTFGOKAEK 2013/49). Medical documentation for each of the selected patients was available. MDCT examinations were performed for various reasons including follow-up of known abdominal disorders, primary or metastatic tumor investigations of different organs, vascular pathologies, and to evaluate infectious diseases. Patients with 

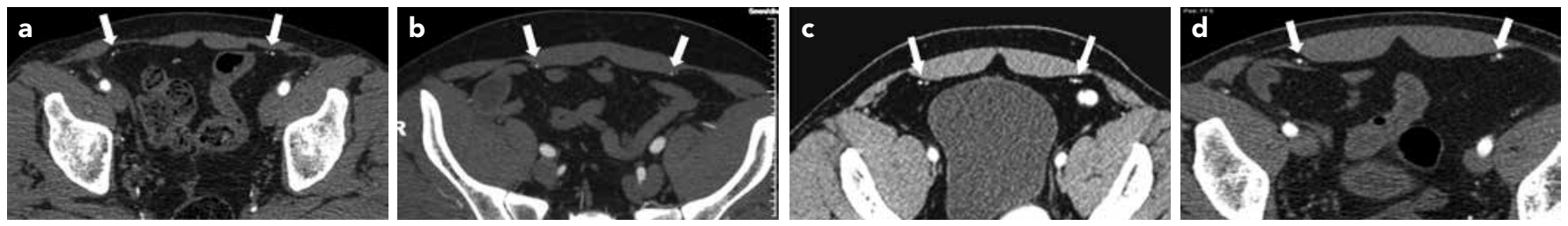

FIG. 1. a-d. Contrast-enhanced CT images of the lower abdomen show a single artery and single vein bilaterally (a), a single artery and two veins bilaterally (b), a single artery and single vein on the right side and a single artery and two veins on the left side (c), a single artery and two veins on the right side and a single artery-single vein on the left side (d) (arrows)

abdominal wall deformities, large abdominal mass, massive ascites, vascular thromboses and collaterals, large abdominal wall hernia, or diastasis recti were excluded. Two hundred consecutive adult patients were enrolled in the study. The age range was 18-89 years (mean, 44 years). One hundred ten patients were women and 90 were men.

\section{MDCT examination}

Computed tomography examinations were performed using a two-detector row CT scanner (Hispeed NXi Dual; GE Medical Systems, Milwaukee, Wisconsin, USA), according to our standard departmental protocol, and included multiplanar reformations. Scan parameters were: $80-120 \mathrm{kVp}$ (peak), 100-150 mAs, 0.5-second gantry rotation, $5 \mathrm{~mm} \times 3 \mathrm{~mm}$ collimation, $3 \mathrm{~mm}$ axial increment, and 1.5-2 mm multiplanar reconstruction image thicknesses. CT angiographic evaluation scan parameters were: $100-120 \mathrm{kVp}, 100-$ $150 \mathrm{mAs}$, 0.5-second gantry rotation, $4 \mathrm{~mm} \times 2 \mathrm{~mm}$ collimation, 2 $\mathrm{mm}$ axial increment, and 1-1.5 mm multiplanar reconstruction image thicknesses. All patients underwent craniocaudal scanning in the supine position from the supradiaphragmatic to the symphysis pubis level, inferiorly, during a single breath hold. Contrast material was given at a rate of 1.5-2.0 mL/kg (max: $150 \mathrm{~mL}$ ) of body weight via the antecubital vein using a mechanical power injector with a speed of $3.0 \mathrm{~mL} / \mathrm{sec}$ and an 18-20-gauge catheter. To start the examination, the Bolus tracking technique was selected by placing a cursor upon the proximal abdominal aorta and arranging the HU value to 100150. Arterial and venous phases of the examinations were started at 25-35 seconds ( $\mathrm{sec}$ ) and 60-70 sec, respectively.

\section{Image analysis}

Image analysis was performed on reformatted coronal images. All data were post-processed using a commercially available workstation (AW Volume Viewer 1.2, GE Medical Systems). Coronal maximum intensity projection (MIP) and multiplanar reconstruction (MPR) images were obtained for all subjects. Reconstructed images were evaluated by two radiologists (HG and OT) at the same time by means of consensus. According to the number of inferior epigastric veins (Figure 1), inferior epigastric vessel arrangements were divided into four groups, as seen in Table 1. The distance between the IEA and midline was measured at three levels: origin, umbilical, and midlevel between the origin and umbilical levels (Figure 2). For IEAs bifurcation, at any level, the distance to the midline was measured from the lateral side.

\section{Statistical analysis}

All statistical analyses were performed with Statistica 7 statistical software. Parametric variables were compared using Student's t-test, and categorical variables were compared using the $\chi^{2}$ test. $\mathrm{p}<0.05$ was considered statistically significant.

\section{RESULTS}

There were 96 (48\%) vein-artery-vein arrangements and $104(52 \%)$ vein-artery arrangements on the left side. On the right side, 98 (49\%) vein-artery-vein arrangements and 102 $(51 \%)$ vein-artery arrangements were depicted. Patient number and frequency of the groups, according to the inferior epigastric vessel combinations, are tabulated in Table 1. A single vein and artery on both sides (group 1) was the most frequently encountered type (41.5\%). Arrangements of the IEA and veins according to the number of veins (vein-artery-vein or vein-artery) revealed no sex predilection at three levels.

Mean distances and the distance ranges between IEAs and the midline, at the three levels, are documented in Table 2. Mean distances on the right and left sides were 4.01 and 4.47 $\mathrm{cm}$ at the umbilical level, 3.81 and $4.26 \mathrm{~cm}$ at the midlevel, and 5.62 and $5.51 \mathrm{~cm}$ at the origin level, respectively. Distances measured at the origin level of the IEA were found to be the longest. Measurement differences between the three levels were highly significant $(\mathrm{p}<0.05)$, on both sides. Right-to-left differences at the three levels were not statistically significant. The distances and distance ranges in men and women are tabulated in Table 3. Male-to-female differences were not significant at any of the three levels or on both sides, except for the right distal level $(p=0.022)$. With respect to the number of veins ( 1 or 2$)$, the measurement differences were not statistically significant

TABLE 1. Patient number and frequency of groups according to the combinations of the IEAs and inferior epigastric veins

\begin{tabular}{clcc}
\hline Group & \multicolumn{1}{c}{ Types } & Patient No. & Frequency (\%) \\
\hline 1 & Bilateral V-A & 83 & 41.5 \\
2 & Bilateral V-A-V & 77 & 38.5 \\
3 & Right V-A, left V-A-V & 19 & 9.5 \\
4 & Right V-A-V, left V-A & 21 & 10.5 \\
\hline
\end{tabular}

$\mathrm{V}-\mathrm{A}$ : vein-artery; $\mathrm{V}-\mathrm{A}-\mathrm{V}$ : vein-artery-vein 
TABLE 2. Mean distances and distance ranges of the proximal, middle and distal levels on the right and left

\begin{tabular}{|c|c|c|c|c|c|c|}
\hline & \multicolumn{2}{|c|}{ Proximal } & \multicolumn{2}{|c|}{ Middle } & \multicolumn{2}{|c|}{ Distal } \\
\hline & Right & Left & Right & Left & Right & Left \\
\hline Mean distance $(\mathrm{cm})$ & $5.62 \pm 0.09$ & $5.51 \pm 0.10$ & $3.81 \pm 0.13$ & $4.26 \pm 0.13$ & $4.01 \pm 0.14$ & $4.47 \pm 0.15$ \\
\hline Distance range $(\mathrm{cm})$ & $4.15-7.78$ & $2.72-7.51$ & $1.36-6.90$ & $1.90-6.69$ & $0.71-8.59$ & $2.06-8.14$ \\
\hline
\end{tabular}

TABLE 3. The distances and distance ranges in men and women on the right and left are tabulated. Male-to-female differences were not significant at any of the three levels or on both sides, except for the right distal level $(\mathrm{p}=0.022)$

\begin{tabular}{|c|c|c|c|c|c|c|c|c|c|c|c|}
\hline \multicolumn{4}{|c|}{ Proximal } & \multicolumn{4}{|c|}{ Middle } & \multicolumn{4}{|c|}{ Distal } \\
\hline \multicolumn{2}{|c|}{ Right } & \multicolumn{2}{|c|}{ Left } & \multicolumn{2}{|c|}{ Right } & \multicolumn{2}{|c|}{ Left } & \multicolumn{2}{|c|}{ Right } & \multicolumn{2}{|c|}{ Left } \\
\hline Men & Women & Men & Women & Men & Women & Men & Women & Men & Women & Men & Women \\
\hline $5.60 \pm 0.14$ & $5.64 \pm 0.14$ & $5.49 \pm 0.16$ & $5.54 \pm 0.13$ & $3.85 \pm 0.13$ & $3.79 \pm 0.18$ & $4.29 \pm 0.22$ & $4.24 \pm 0.17$ & $4.21 \pm 0.17$ & $3.86 \pm 0.20$ & $4.56 \pm 0.24$ & $4.41 \pm 0.20$ \\
\hline $4.19-7.5$ & $4.15-7.78$ & $3.25-7.51$ & $2.72-7.10$ & $2.08-6.9$ & $1.36-6.29$ & $2.08-6.69$ & $1.90-6.45$ & $2.00-8.59$ & $0.71-7.20$ & $2.06-8.14$ & $2.25-7.29$ \\
\hline
\end{tabular}

at all three levels. Additionally, a total of 56 IEA bifurcations were depicted all 200 patients. Thirteen of the 56 bifurcations occurred only on the right side, 11 only on the left side, and 32 on both sides.

\section{DISCUSSION}

The inferior epigastric artery (IEA) arises medially from the distal external iliac artery, just proximal to the inguinal ligament. It curves forward in the extraperitoneal tissue and journeys superiorly to the posterior wall of the rectus sheath beneath the rectus abdominis muscle, and finally connects with the internal mammary arteries superior epigastric branches. Due to the anatomic position of the IEA, patients undergoing abdominal wall procedures may have a high risk of injury.

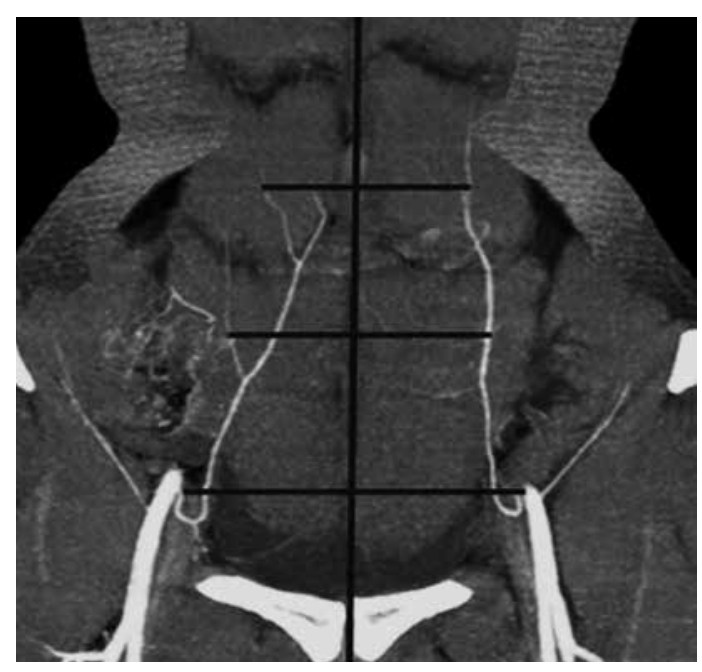

FIG. 2. Seventy one-year-old woman with pelvic pain. Curved planar reformatted maximum-intensity-projection MDCT image shows an artery on both sides. The measurement lines are shown between IEAs and the midline at three levels. The lines extend parallel to each other
However, radiologic studies documenting the course of inferior epigastric vessels, their artery-vein variations, and their distances to the midline are limited in number (1-4).

During percutaneous transabdominal procedures, serious complications may occur due to vessel injury. These injuries occur in $0.2 \%$ to $2.0 \%$ of reported cases in the literature (1, $7-10)$. The most commonly injured vessels in these procedures are the epigastric vessels $(2,11,12)$.

Inferior epigastric vessel injuries may result in different clinical presentations, such as bleeding at laparoscopy (13), pseudoaneurysm after right hemicolectomy by median laparotomy (14), pseudoaneurysm and arteriovenous fistula after hysterectomy and right oophorectomy (15), rectus sheath hematoma in patients with renal disease after insertion of a peritoneal dialysis cannula (16), myonecrosis of the rectus abdominis muscle after undergoing pelvic surgery (17), retroperitoneal hemorrhage from laceration of the inferior epigastric artery during catheterization (18), and life-threatening hematoma associated with paracentesis (19). Inadvertent puncture of the IEA may be potentially fatal, as reported by Todd (20), for example, as a result of inadvertent puncture of the inferior epigastric artery during needle biopsy. In the case of aortoiliac occlusive disease, the inferior epigastric arteries may become an important part of the collateral blood provided to the lower extremities by reversal of the blood flow. Thus, its injury can give rise to the worsening of lower extremity ischemia (21, 22). Autologous reconstruction with abdominal tissue is one of the best options after some operations. Accurate evaluation of the vascular anatomy of the abdominal wall, in reconstruction with inferior epigastric vessels, is very valuable in improving the operative strategy in abdominal flaps. Damage to the inferior epigastric artery also means that harvesting the rectus abdominis muscle flap becomes impossible $(1,23)$.

Saber et al. (1) investigated the location of the superior and inferior epigastric vessels, from the midline at five levels, and described an area between 4 and $8 \mathrm{~cm}$ from the midline as a safe zone of entry for the anterior abdominal wall. However, 
our results for inferior epigastric vessels distances from the midline, at each level as shown in Table 2, did not correlate when compared with their report and were $1.5-2 \mathrm{~cm}$ larger than theirs. Pun et al. (24) documented the distance between the inferior epigastric vessels, superficial circumflex iliac vessels, and the midline at 3,5, and $7 \mathrm{~cm}$ from the pubic symphysis using ultrasound. At the proximal level, our results were similar to those of Pun et al. (24), but differed at the other two levels. The main reason for this difference may be attributed to the use of ultrasound - a user-dependent modality - in their study compared with the use of contrast-enhanced MDCT which more accurately demonstrates the vascular system, used in the current study.

Sriprasad et al. (2) reported the value of using ultrasound and CT when determining abdominal vessel localizations to avoid vascular injury. They described the distance between the inferior epigastric vessels and the midline at the umbilicus and anterior superior iliac spine levels using ultrasonography. At the level of the umbilicus, the epigastric vessels were 4.6 and $4.9 \mathrm{~cm}$ away from the midline on the right side and left side, respectively. At the level of the anterior superior iliac spine, the epigastric vessels were $4.7 \mathrm{~cm}$ on the right side and $4.9 \mathrm{~cm}$ away from the midline on the left side. Measurement results taken at the umbilical (mid) level in the current study differed from those of Sriprasad et al. (2), possibly because measurements were made according to different anatomical landmarks; moreover, ultrasound versus CT methods were employed. Nezhat et al. (25) measured the distance between the inferior epigastric vessels and the midline at the level of the suprapubic trocar placement sites. The distance was $5.5 \mathrm{~cm}$ on the right side and $5.1 \mathrm{~cm}$ on the left side. At this level, our results were slightly different on the right side $(5.6 \mathrm{~cm}$ vs. $5.5 \mathrm{~cm})$ and significantly larger on the left side $(5.5 \mathrm{~cm}$ vs. $5.1 \mathrm{~cm})$.

The presence of the IEA bifurcation and its distance to the midline have not been mentioned in previous studies based on imaging modality techniques. Alonso-Burgos et al. (3) and Masia et al. (4) discussed the anatomical evaluation of the IEA and its perforator branches using MDCT for abdominal flap reconstructions. In El-Mrakby's study, undertaken in 20 cadavers, the presence of a bilateral artery and vein occurred in $10 \%$ of cases, and a bilateral artery and two veins occurred in $90 \%$ of cases (26). In Shafighi's (27) study using 44 cadavers, a double vein was present in $22.7 \%$ on the right side, $34.1 \%$ on the left side, and $13.6 \%$ bilaterally. A single vein was found in $29.6 \%$ of examined cadavers. However, one artery and one vein occurred bilaterally in $41.5 \%$, bilaterally one artery and two veins in $38.5 \%$, only one artery and two veins on the right side in $9.5 \%$, and only one artery and two veins on the left side in $10.5 \%$ in the current study, as shown in Table 1.

In conclusion, the inferior epigastric vessels have variable patterns. Regardless of the abdominal level, the distance from the inferior epigastric vessels to the midline is not constant and varies in the range of 2 to $7 \mathrm{~cm}$. This does not allow for the definition of a precise, safe zone of entry for percutaneous abdominal intervention procedures. Since MDCT exactly maps the inferior epigastric vessels and their morphological variations, and also effectively depicts the distance to the midline using coronal reconstructed images. Mapping inferior epigastric vessels using reconstructed MDCT images is recommended before performing percutaneous abdominal interventions that may cause serious complications.

Ethics Committee Approval: Ethics committee approval was received for this study from the ethics committee of the Trakya University Faculty of Medicine Hospital.

\section{Informed Consent: N/A.}

Peer-review: Externally peer-reviewed.

Author contributions: Concept - H.G., M.D.; Design - H.G., O.T.; Supervision H.G., M.K.D.; Resource - H.G., M.D.; Materials - H.G., M.D.; Data Collection\&/or Processing - H.G., O.T.; Analysis\&/or Interpretation - H.G., O.T.; Literature Search - H.G.; Writing - H.G.; Critical Reviews - H.G., O.T.

Conflict of Interest: No conflict of interest was declared by the authors.

Financial Disclosure: The authors declared that this study has received no financial support.

\section{REFERENCES}

1. Saber AA, Meslemani AM, Davis R, Pimentel R. Safety zones for anterior abdominal wall entry during laparoscopy: a CT scan mapping of epigastric vessels. Ann Surg 2004;239:182-5. [CrossRef]

2. Sriprasad S, Yu DF, Muir GH, Poulsen J, Sidhu PS. Positional anatomy of vessels that may be damaged at laparoscopy: new access criteria based on CT and ultrasonography to avoid vascular injury. $J$ Endourol 2006;20:498-503. [CrossRef]

3. Alonso-Burgos A, Garcia-Tutor E, Bastarrika G, Cano D, MartinezCuesta A, Pina LJ. Preoperative planning of deep inferior epigastric artery perforator flap reconstruction with multislice-CT angiography: imaging findings and initial experience. J Plast Reconstr Aesthet Surg 2006;59:585-93. [CrossRef]

4. Masia J, Clavero JA, Larranaga JR, Alomar X, Pons G, Serret P. Multidetector-row computed tomography in the planning of abdominal perforator flaps. J Plast Reconstr Aesthet Surg 2006;59:594-9. [CrossRef]

5. Piorkowski JR, DeRosier LC, Nickerson P, Fix RJ. Preoperative computed tomography angiogram to predict patients with favorable anatomy for superficial inferio epigastric artery flap breast reconstruction. Ann Plast Surg 2011;66:534-6. [CrossRef]

6. Karunanithy N, Rose V, Lim AK, Mitchell A. CT angiography of inferior epigastric and gluteal perforating arteries before free breast reconstruction. Radiographics 2011;31:1307-19. [CrossRef]

7. Zaki H, Penketh R, Newton J. Gynaecological laparoscopy audit: birmingham experience. Gynecol Endocrinol 1995;4:251-7.

8. Aharoni A, Condea A, Leibovitz Z, et al. A comparative study of Foley catheter and suturing to control trocar-induced abdominal wall haemorrhage. Gynecol Endocrinol 1997;6:31-2.

9. Vasquez JM. Vascular complications of laparoscopic surgery. J Am Assoc Gynecol Laparosc 1994;1:163-7. [CrossRef]

10. Spitzer M, Golden P, Rehwaldt L, Benjamin F. Repair of laparoscopic injury to abdominal wall arteries complicated by cutaneous necrosis. $J$ Am Assoc Gynecol Laparosc 1996;3:449-52. [CrossRef] 
11. Hurd WW, Pearl ML, DeLancey JO, Quint EH, Garnett B, Bude RO. Laparoscopic injury of abdominal wall blood vessels: a report of three cases. Obstet Gynecol 1993;82:673-6. [CrossRef]

12. Lin P. Complications of laparoscopy: strategies for prevention and cure. Obstet Gynecol Clin North Am 1999;26:23-38. [CrossRef]

13. Lavery S, Porter S, Trew G, Margara R, Jackson J. Use of inferior epigastric artery embolization to arrest bleeding at operative laparoscopy. Fertil Steril 2006;86:719.e13-4.

14. Takase K, Kazama T, Abe K, Chiba Y, Saito H, Takahashi S. Pseudoaneurysm of the inferior epigastric artery successfully treated by ultrasound-guided compression. Cardiovasc Intervent Radiol 2004;27:520-2. [CrossRef]

15. Pinero A, Reus M, Agea B, Capel A, Riquelme J, Parrilla P. Conservative management of an arteriovenous fistula of the inferior epigastric artery. Br J Radiol 2003;76:135-6. [CrossRef]

16. Jayawardene SA, Goldsmith DJ. Rectus sheath haematomata in patients with renal disease. Nephrol Dial Transplant 2002;17:1832-5. [CrossRef]

17. Ries AM, Nycum LR, Reed ME. Myonecrosis of the rectus muscle after a Cherney incision. Gynecol Oncol 1998;68:66-8. [CrossRef]

18. Patterson JA, Tilkian AG. Retroperitoneal hemorrhage from inferior epigastric artery. Catheter Cardiovasc Interv 2007;69:926. [CrossRef]

19. Mulpuru SK, Mori NA, Levey RL, Leonardo R. Life-threatening hematoma associated with paracentesis: a case report. Blood Coagul Fibrinolysis 2006;17:491-3. [CrossRef]
20. Todd AW. Inadvertent puncture of the inferior epigastric artery during needle biopsy with fatal outcome. Clin Radiol 2001;56:989-90. [CrossRef]

21. Krupski WC, Sumchai A, Effeney DJ, Ehrenfeld WK. The importance of abdominal wall collateral blood vessels. Planning incisions and obtaining arteriography. Arch Surg 1984;119:854-7. [CrossRef]

22. Sistrom CL, Reiheld CT, Elliot H. Reversal of flow in the inferior epigastric arteries, Doppler ultrasonographic findings and significance. J Ultrasound Med 1995; 14:183-91.

23. Verbist J. Pseudoaneurysm of the inferior epigastric artery. Acta Chir Belg 1997;97:196-8.

24. Pun TC, Chau MT, Lam C, Tang G, Leong L. Sonographic localization of abdominal vessels in Chinese women: its role in laparoscopic surgery. Ultrasound Obstet Gynecol 1998;11:59-61. [CrossRef]

25. Nezhat CH, Nezhat F, Brill AI, Nezhat C. Normal variations of abdominal and pelvic anatomy evaluated at laparoscopy. Obstet Gynecol 1999;94:238-42. [CrossRef]

26. El-Mrakby HH, Milner RH. The vascular anatomy of the lower anterior abdominal wall: a microdissection study on the deep inferior epigastric vessels and the perforator branches. Plast Reconstr Surg 2002;109: 539-43. [CrossRef]

27. Shafighi M, Schwabegger AH, Michelle E, Gurunluoglu R. A cadaver study: the course of the inferior epigastric vessels. Plast Reconstr Surg 2003;112:341-3. [CrossRef] 